\title{
Negative Priming within a Stroop Task in Children and Adolescents with Attention-Deficit Hyperactivity Disorder, their Siblings, and Independent Controls
}

\author{
Hanna Christiansen ${ }^{1}$ and Robert D. Oades ${ }^{2}$ \\ 1. Philipps-University Marburg 2. University of Duisburg-Essen
}

2010 Journal of Attention Disorders, 13, 497-504

This is the reformatted manuscript submitted - prior to publication in its final form at doi: $10.1177 / 1087054708325974$

\begin{abstract}
:
Objective: Negative priming (NP), a slowed response to a stimulus, was previously ignored. Response times in NP task conditions were compared with the interference provided by congruent/incongruent stimuli in a Stroop condition in the same task in children diagnosed with attention-deficit hyperactivity disorder (ADHD), their unaffected siblings, and independent controls. Method: Speed, accuracy, and variability of responses were compared using a computerized NP Stroop test for 35 children with ADHD, 24 siblings without diagnosis, and 37 independent healthy controls aged 6 to 17 years. Results: NP was evident at test onset for congruent trials in children without a diagnosis and was reduced initially in those with ADHD occurring in the absence of a significant Stroop interference effect and independently of age or symptom severity. Incongruency masked NP effects. Cases showed more intra-individual response-time variability. Conclusions: Both NP in normal children and its reduction in ADHD cases attenuated across trials reflecting the increased facilitation from previous stimulation.
\end{abstract}

Keywords: ADHD; attention; negative priming; Stroop; priming; variability

Authors' Note: The authors are grateful for financial support from NIH Grant R01MH62873 to S. Faraone and the IMAGE consortium in which the Essen group is a participant. Robert D. Oades was also in receipt of an investigator-initiated grant from Janssen-Cilag. The authors are also grateful to Gregor Volberg for writing the NP-Stroop program and Kristina van Leewen for running it. Correspondence concerning this article should be addressed to RDO, University Clinic for Child and Adolescent Psychiatry and Psychotherapy, The University of Duisburg-Essen, Virchowstr. 174, D-45147 Essen, Germany; E-Mail: robert.oades@uni-due.de.

\section{Introduction:}

Young people with attentiondeficit/hyperactivity disorder (ADHD) may show periods of excessive activity or restlessness, respond impulsively, have impaired motor coordination, and difficulties in paying attention (Diagnostic and Statistical Manual of Mental Disorders; 4th ed., American Psychiatric Association, 1994). The nature of what underlies this latter cognitive impairment has been a particular source of controversy.
Studies of sustained attention during continuous performance report slower and more inaccurate responses (Nigg, Hinshaw, \& Halperin, 1996) and poorer signal detection in children with ADHD (Oades, 2000); however, the vigilance aspects of performance over time do not identify children with ADHD (van der Meere, Wekking, \& Sergeant, 1991). Douglas (1988) maintained that an inability to ignore distracting stimuli is basic to the difficulty of ADHD children in 
focusing attention. Yet recent studies of executive functions necessary for controlled attention did not support a general deficit. Indeed, children with ADHD showing inattentive features proved less sensitive to interference (measured by the choice of words of opposite meaning) than the healthy controls (Geurts, Verte, Oosterlaan, Roeyers, \& Sergeant, 2005).

Studies of more automatic attentional processes have been few. Electrophysiological reports on the detection of auditory stimulus change and the ability to switch processing accordingly support hypotheses about altered and often delayed development in the right hemisphere of children with ADHD (Mismatch negativity; Oades, DittmannBalcar, Schepker, \& Eggers, 1996). Potentials elicited by the stop stimulus in the stop task are sensitive to whether the subject can switch attention and withhold response successfully. This sensitivity is lost in young adults with ADHD and demonstrates that impaired stop performance in ADHD is at least partly under poor attentional control (Bekker, Kenemans, Hoeksma, Talsma, \& Verbaten, 2005).

Both the stop and interference tasks concern the influence of a previous stimulus in responding to the current stimulus. Classic investigations of this have used the Stroop task and positive/negative priming. The interference condition of the Stroop task requires the naming of the color; a word is printed in one color and what it says denotes another color. Reviews of over 30 studies of ADHD cases on the Stroop task (Boonstra, Oosterlaan, Sergeant, \& Buitelaar, 2005; Schwartz \& Verhaeghen, in press) show that it is most often an impairment of the "naming of colors" rather than the interference effect that prolongs response latencies. The question remains whether priming effects are normal in ADHD.
Given that negative priming (NP) is represented by a slowed response to a target that has just been a non-target, we ask in this study whether interference represented by NP is normal in children with ADHD. This raises the question, first, whether normal children in this age group can be expected to show NP? The results from several test forms show that although prepubertal children may not show conceptual NP like young adults, as in a presentation with Stroop stimuli (Tipper, Bourque, Anderson, \& Brehaut, 1989), NP can be demonstrated using the location and identity of simple forms, such as a star, triangle, or square (Simone \& McCormick, 1999; Tipper \& McClaren, 1990). Studies of the development of NP in 150 children showed NP to be present from about the age of 5 years for both a flanker presentation of blobs requiring the color of the central one to be named and a presentation of Stroop stimuli on cards. There was little, if any at all, alteration of the effect up to 12 years of age (Pritchard \& Neumann, 2004). The effect was present in two thirds of 5-year-olds and in nearly 4 out of 512 -year-olds.

Reductions of NP have been reported on letter or syllable flanker tasks for cases with ADHD (Marriott, 1998; Ossmann \& Mulligan, 2003; Ozonoff, Strayer, McMahon, \& Filloux, 1998). But a reduction of the NP effect was not recorded for children or adolescents with ADHD on Stroop or colored flanker stimulus presentations (Gaultney, Kipp, Weinstein, \& McNeil, 1999; Pritchard, Healey, \& Neumann, 2006; Pritchard, Neumann, \& Rucklidge, 2007). Specifically, Pritchard et al. (2007) reported on adolescents with ADHD without medication or comorbid disorders of whom two thirds were of the inattentive subtype. The ADHD group showed NP on a color flanker task and a Stroop interference effect like the controls: Their 
Stroop NP was proportionately but nonsignificantly reduced.

In this study, we used a Stroop task so as to be able to compare NP and Stroop interference effects and to compare these results with previous reports. We restricted $A D H D$ cases to the combined type to reflect the most widely reported subtype and male gender prevalence. We also compared younger with older cases for whom symptoms may abate. If symptom severity plays a role in attentionrelated processing measured by NP (as predicted) then this should become evident both by associations with ratings and by comparison with siblings without the ADHD diagnosis.

\section{Materials and Methods:}

Families, recruited from the outpatient department, contained at least one child with ADHD and one sibling without ADHD: Both parents were available in accordance with an extensive genetic study (Asherson \& Image Consortium, 2004). The first 35 families were selected, interviewed by a trained rater, and the cases diagnosed with DSM-IV combined subtype of ADHD using the Parent Assessment of Children's Symptoms (PACS; Chen \& Taylor, 2006; Taylor, Sandberg, Thorley, \& Giles, 1991) and a scoring algorithm developed at the Institute of Psychiatry, London. The PACS is a semi-structured, standardized, trained investigator-based interview where the inter-rater reliability is high with productmoment correlations between pairs of interviewers ranging from .79 to .96 (Taylor, Schachar, Thorley, \& Wieselberg, 1986). Symptoms and function were also assessed with the Conners parent and teacher ratings, the strengths and difficulties questionnaire and the clinical global assessment (Conners, 2002; Goodman, 2001). The parent and teacher ratings correlated well with each other across groups ( $n=96, r=+0.55, p<.00001$ ). Comorbid diagnoses (sometimes multiple) among the ADHD cases included 23 children with oppositional defiant disorder, 18 children with conduct disorder, and 14 children with an internalizing mood/anxiety disorder. Exclusion criteria were the presence of pervasive developmental disorders, epilepsy, an IQ below 70, and medical or genetic disorders that mimic ADHD. If subjects had been receiving stimulant medication, this was withdrawn at least two days before testing.

Independent healthy control children were recruited through advertisement and a local school. They, like the healthy siblings, were screened with the Conners scales $(T<65 ;$ Table 1$)$. Although none of the siblings in this group received a diagnosis of ADHD, some scored $>65$ on one of the two Conners' scale ratings. These were subject to a separate analysis and are termed siblings with high-S and without ADHD symptoms termed as low-S. Both control groups and the parents claimed that the subjects were free of medication affecting the nervous system, and no participants were color blind. All subjects had an estimated IQ $>75$ based on 4 WISC subtests (information, picture arrange-ment, similarities, and blockdesign; Sattler, 1992). As the subjects were involved in further neuropsychological investigation they were all paid 25 Euros at the end of their involvement. In total, data were analyzed for 35 children with ADHD, 24 siblings without ADHD, and 37 independent healthy controls (see Table 1 for group features).

The study protocol was reviewed and approved by both the board of University of Psychiatry Clinics and the Ethics Committee of the Faculty of Medicine according to the criteria of the Declaration of Helsinki. After the procedures had been described, all subjects and caregivers gave verbal and written informed consent. 
Table 1

Group Characteristics (Experiment 1)

\begin{tabular}{|c|c|c|c|c|c|c|}
\hline & $\mathrm{N}$ & $\begin{array}{c}\text { Gender } \\
\mathrm{m} / \mathrm{f}\end{array}$ & $\begin{array}{l}\text { Age } \\
\text { years }\end{array}$ & $\begin{array}{l}\text { IQ } \\
\text { brief }\end{array}$ & $\begin{array}{l}\text { Conners } \\
\text { teacher- }\end{array}$ & $\begin{array}{l}\text { Conners } \\
\text { parent ratings }\end{array}$ \\
\hline & & & (Means & : standard devia & ons in parentl & heses) \\
\hline ADHD & 35 & $32 / 3^{\#}$ & $11.2(2.4)$ & $101.7(13.9)$ & $75.1 \quad(8.3)$ & $76.9(8.3) * *$ \\
\hline Siblings (Sibs) & 24 & $11 / 13$ & $11.3(3.3)$ & $107.3(11.9)$ & $55.8(15.1)$ & $55.8(13.5)$ \\
\hline Controls (Cs) & 37 & $15 / 22$ & $11.5(1.9)$ & $108.7(2.0) *$ & $56.7(21.2)$ & 49.1 \\
\hline Sibs (high-S) & 8 & $5 / 3$ & $11.5(1.2)$ & $105.6 \quad(9.8)$ & $73.9 \quad(9.9)$ & $66.0(15.7)^{\S}$ \\
\hline Sibs (low-S) & 16 & $6 / 10$ & $11.3(0.9)$ & $108.1(13.1)$ & $46.8 \quad(1.6)$ & 47.8 \\
\hline
\end{tabular}

Note: Sibs $=$ siblings $; \mathrm{Cs}=$ Controls; $\mathrm{ADHD}=$ attention-deficit hyperactivity disorder. Numbers in parentheses indicate standard deviations.

\#. There were fewer females, $F(2,92)=14.1, p<.00001$, and higher Conners ratings, $* * F(2,93)=15.4$, in the ADHD than in the other groups. Controls had a higher IQ than the ADHD cases, ${ }^{*} F(1,70)=5.1$.

$\S$. Sibs (high/low-S) are subgroups of siblings with no diagnosis but with high $(t>65)$ or low ratings $(t<65)$ on the Conners' questionnaires, $F(1,22)=65.2, p<.00001 .{ }^{*} p<.03 * * p<.00001$

A software program was written to generate a sequence of single words (1.5 $\mathrm{cm}$ high) denoting the colors red, yellow, green, and blue that could be written in any of these colors. The subject sat $1 \mathrm{~m}$ from the screen and was required to respond to the color seen on one of four keys. The keys were labeled and colored appropriately, and their order was also illustrated immediately below the screen. First, it had been noted on the brief IQ test that the child could read, which was confirmed by their correct identification of words denoting color presented on the computer screen. Following a practice run there were 6 experimental blocks each of 48 trials. A trial began with a fixation cross in the middle of the screen (300 ms) and was followed after $600 \mathrm{~ms}$ by a colored word that remained on screen until a response was made (maximum $4 \mathrm{~s}$ ). After a response there was an inter-trial interval of 1,000 ms. Response times (RTs) $>3000$ and $<200 \mathrm{~ms}$ were rejected prior to analysis. The stimulus sequence was specified to deliver 144 congruent (color and word were concordant) and 144 incongruent trials (the word denoted a color other than the one in which it is seen): In addition, there were 38 congruent and 38 incongruent trials placed to detect the NP effect (i.e., the color denoted on the previous trial that received no response became the color seen and presented for response). Note that although NP on an incongruent trial refers to the color and not the word, the incongruency of the trial entails overcoming the Stroop interference effect. Auditory feedback was presented. A deep beep meant that a non-response key had been hit, and a high beep meant that the correct response key had been hit. Errors and RTs were recorded throughout whereby the first trial in each block was discarded prior to analysis.

Group characteristics were compared with analyses of variance (ANOVA). Multivariate analyses (MANOVA) for the three groups of subjects were extended to RTs, difference values reflecting NP, and interference effects and repeated measures across five test trial blocks. Trends are reported as $p<.1$ and 
significance as $p<.05$. Where post hoc tests were needed to confirm the locus of effect, Tukey or Student $t$ tests are reported. For explorative Pearson two-tail correlations of performance with subject characteristics, significant relationships may be taken conservatively at $p<.01$. Covariance analyses were performed initially for age, gender, and symptom ratings, but only the covariate of age was routinely used in view of the wide age range of the subjects. RT data did not vary significantly from a normal distribution according to the Kolmogorov-Smirnov test either on the four conditions of the first trial blocks $(d=.08-.18, p>.2)$ nor on the grand means of the difference scores for the NP and interference effects $(d=.09-.12, p$ $>$.2).

Table 2

Mean reaction times ( $R T)$, errors and the mean standard deviations (SD) on congruent vs. incongruent trials (without priming) on the Stroop-task: ADHD cases, siblings and independent controls

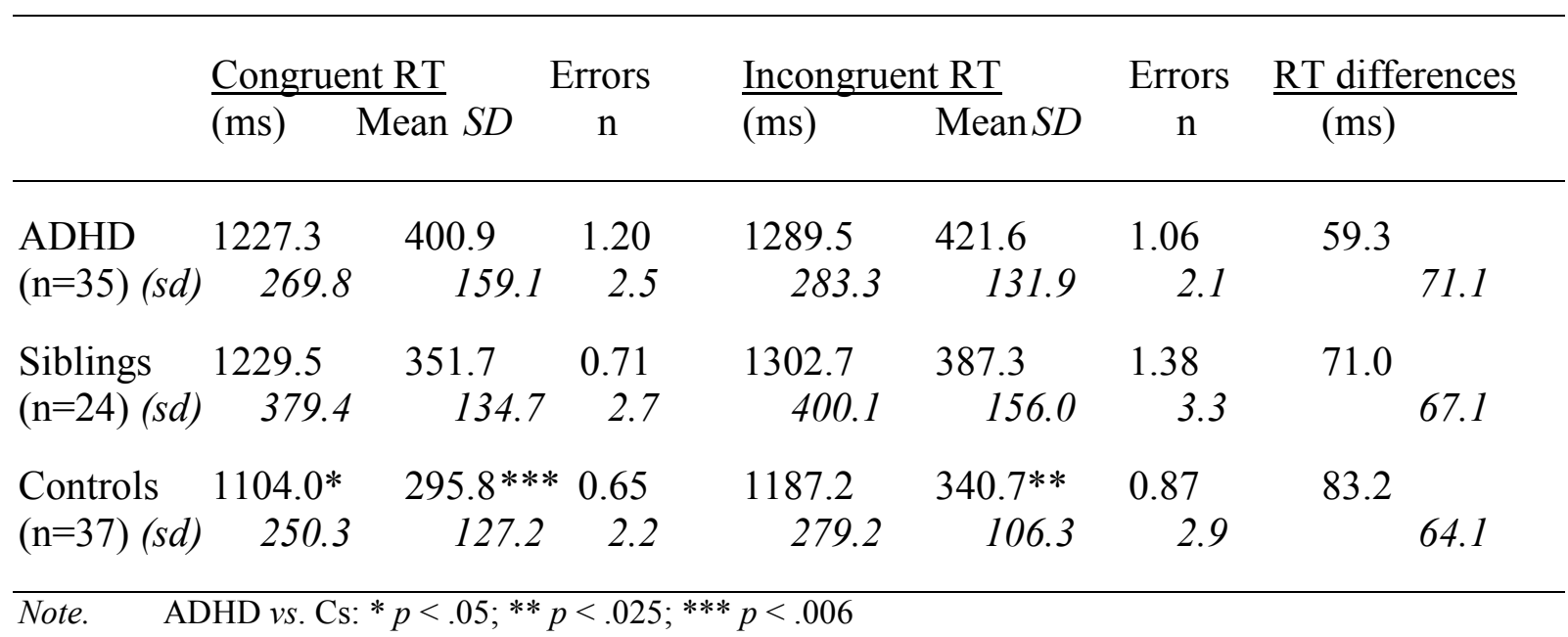

\section{Results}

A comparison of RTs of the cases, siblings, and controls in the 4 conditions $( \pm$ priming, \pm congruency) showed a trend toward longer latencies in the ADHD cases, $F(8,180)=1.8, p=.087, \eta^{2}=.07$. This was explained by longer RTs of cases in stimulus-congruent color-naming trials (without NP) than those of the controls, $t_{70}+2.0, p=.048$ (Table 2). The siblings' mean RT was similar to the ADHD cases but not significantly different from the controls. The pattern was descriptively similar for the RTs to incongruent stimuli.

Variability of RT measured by the standard deviation was also moderately larger in the ADHD cases than in the controls in all four conditions, $F(2,95)=$ 2.9-5.0, $p=.06-.009, \eta^{2}=.06-.10$ (Table 2).
The coefficients of variation (100 x SD / mean $\mathrm{RT}$ ) varied little between conditions (ADHD, range 32.0-34.0; controls 26.229.9) but were significantly larger in the ADHD group versus controls, with siblings showing intermediate values, for example, congruent-no-NP condition, $F(2,95)=5.3$, $p=.007, \eta^{2}=.1$. Although very few errors were made by members of any group, the controls made non-significantly fewer errors on both the congruent and incongruent trials than the other two groups (Table 2 ).

There was no significant difference between groups on the Stroop interference effect between incongruent and congruent trials, even though the effect recorded in the cases was shorter by $>20 \mathrm{~ms}(28.7 \%)$ than that observed in 
controls, $F(2,93)=1.1, p=.33, \eta^{2}=.02$, (Table 2).

A MANOVA conducted for ascertaining the NP effect (with RT on trials with NP, without RT on trials without NP) in congruent and incongruent trials for the three main groups was only significant for the congruent condition, $F(2,93)=3.5, p$ $=0.03, \eta^{2}=.07$, where siblings showed most NP (Table 3). The cases showed significantly less NP than siblings on congruent trials. Indeed, measures of NP in congruent and incongruent trials did not correlate with each other $(r=+0.07, p$
$=.51$ ) indicating a confounding rather than an additive effect for Stroop interference and NP. Separate analyses for subjects aged more or less than 11 years did not show that NP was recorded significantly more in the younger or older subjects, $F$ $(5,95)=1.51, p=.19$. Furthermore, $a$ comparison of the NP effect in the small number of siblings with high ratings on the Conners scale $(n=8)$ versus those with low scores $(n=16)$ also showed no significant differences, $F(1,22)=2.07, p=$ .16 .

Table 3

Mean reaction times $(R T)$, errors and the mean of the standard deviations (SD) on negative priming trials in the congruent (NP-cong) and incongruent conditions of the Stroop-task (NPincong): ADHD cases, siblings and independent controls

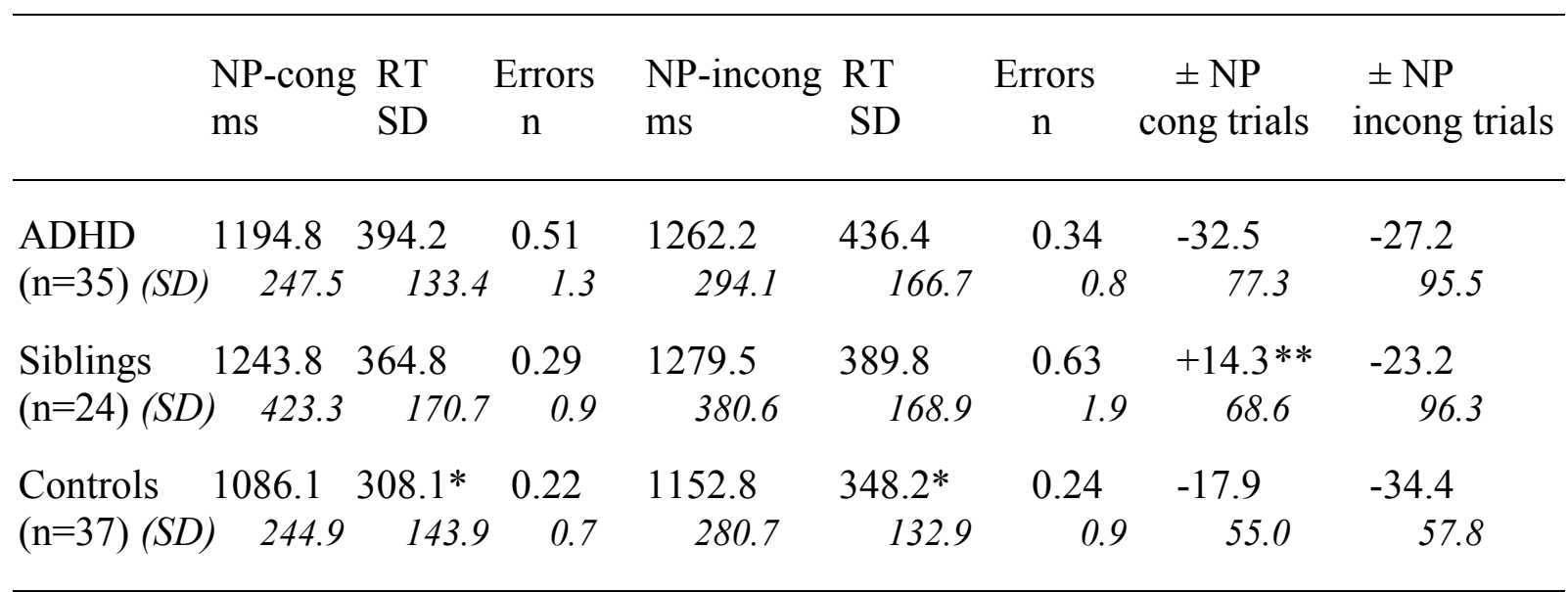

Note. Note: RT = reaction time; NP-Cong = negative priming trials in the congruent; NP-Incong = incongruent conditions of the Stroop Task; ADHD = attention-deficit hyperactivity disorder. * Controls vs. Cases, Tukey HSD $p<.05 ; * *$ Siblings vs. Cases, $p<.03$

Focusing on congruent stimulus presentations, we examined performance across trial blocks (repeated measures for five trial blocks, Table 4). First, there was a marked main effect of test, $F(3.73,89)=$ 6.16, $p<.0001, \eta^{2}=.22$, Greenhouse Geisser 0.93. This showed a linear evolution from negative to positive priming in all groups, $F(1,92)=24.5, p<$ $.0001, \eta^{2}=.21$. Although there was no interaction with group, $F(7.5,178)=.52$, there was a moderate effect of group, $F$ $(2,92)=3.8, p=.026, \eta^{2}=.08$. Here, NP was evident in the early test trials in siblings and controls, but not in the ADHD cases. The priming effect in siblings and controls remained more positive than in the ADHD cases (i.e., a longer RT on NP trials) across trial blocks ( $p=.019$ : Table 4). It may be noted that the variability of group performance, using structural equation modeling (SEM) remained quite 
similar and stable for all groups throughout the test. Consideration of the factors of $1 \mathrm{Q}$, age, or gender made no significant contribution in covariate analyses.

Finally, we conducted a correlational analysis across all subjects for (a) associations of the Stroop interference and NP effects on performance, and (b) between NP performance and symptom ratings.

Intriguingly, though there was a positive association between the Stroop interference effect and NP on congruent trials $(r=+0.33, p<.001)$, a negative relationship of Stroop effect with NP measures in incongruent trials $(r=-21, p=$ .047) was also observed. These relationships were not evident in younger members of the three groups ( $\leq 11$-yearold). The effect was largely carried by the older cases and siblings rather than the controls (> 11-year-old: ADHD, $\mathrm{n}=22, r=$ $0.61, p<.003$; siblings: $\mathrm{n}=10, r=0.64, p<$
.05 ; controls: $\mathrm{n}=21, r=0.26, p=.26)$. Unlike measures of NP, there was a strong relationship for the degree of Stroop interference with errors made on all trial types ( $\pm N \mathrm{~N}, \pm$ congruence: $r=+.37$ to + $.42, p<.0001)$.

Conners parent and teacher symptom ratings correlated well with each other $(r$ $+.82, p<.0001$ ) but were unrelated to NP on congruent or incongruent trials or to the Stroop interference effect. Although there were no associations between the standard deviations of these effects with ratings, there were strong associations for the teacher and parent ratings with the standard deviations and coefficients of variance in all trial types (congruent, with no NP: $r+.38 / .31, p<.0001$; incongruent, with no NP: $r+.29 / .29, p=.005-.004$; congruent, with NP: $r+.22 / .22, p<.035$; incongruent, with NP: $r=+.24 / .24, p=$ $.02)$.

Table 4

The mean RT difference values (ms) and standard error (SE) for the NP effect (trials with NPminus- trails without NP) in 5 successive trial blocks for congruent stimulus presentation

\begin{tabular}{|c|c|c|c|c|c|}
\hline $\begin{array}{l}\text { Trial block: } \\
\text { Group : RT }\end{array}$ & $1^{\text {st }}$ & $2^{\text {nd }}$ & $3^{\text {rd }}$ & $4^{\text {th }}$ & $5^{\text {th }}$ \\
\hline $\begin{array}{l}\text { ADHD } \\
\qquad(n=34) \mathrm{SE}\end{array}$ & $\begin{array}{r}-8.3 \\
28.2\end{array}$ & $\begin{array}{r}+34.5 \\
31.3\end{array}$ & $\begin{array}{r}-57.6 \\
31.0\end{array}$ & $\begin{array}{r}-58.9 \\
31.6\end{array}$ & $\begin{array}{r}-120.3 \\
32.7\end{array}$ \\
\hline $\begin{array}{l}\text { Siblings } \\
\qquad(n=24) \mathrm{SE}\end{array}$ & $\begin{array}{r}+74.5 \\
33.5\end{array}$ & $\begin{array}{r}+85.0 \\
37.2\end{array}$ & $\begin{array}{r}-19.1 \\
36.9\end{array}$ & $\begin{array}{r}-24.3 \\
37.6\end{array}$ & $\begin{array}{r}-34.6 \\
38.9\end{array}$ \\
\hline $\begin{array}{l}\text { Controls } \\
\qquad(n=37) \mathrm{SE}\end{array}$ & $\begin{array}{r}+26.0 \\
27.0\end{array}$ & $\begin{array}{l}+2.6 \\
30.0\end{array}$ & $\begin{array}{r}-13.2 \\
29.7\end{array}$ & $\begin{array}{r}-37.7 \\
30.3\end{array}$ & $\begin{array}{r}-51.8 \\
31.3\end{array}$ \\
\hline
\end{tabular}

Note: $\mathrm{RT}=$ reaction time; $\mathrm{SE}=$ standard error; $\mathrm{ADHD}=$ attention deficit hyperactivity disorder. Repeated measures analysis showed significant main effects for group and task with no significant interaction (see text). 


\section{Discussion:}

In a computer presentation of the Stroop task ADHD, cases tended to show slower RTs and increased intra-individual RT variability in all conditions. The increases were most evident on congruent color-naming trials, whereas the degree of Stroop interference did not differ significantly between groups. During the initial trials, NP was evident in controls and siblings, and reduced in the ADHD cases. However, for all groups, the NP condition acquired the facilitatory characteristic of positive priming across trials. Neither age nor symptom severity influenced the expression of the priming effects.

\section{Stroop Interference and NP Measures}

The absence of significant group differences in the Stroop interference effect is consistent with recent reviews of 35 studies (see the opening paragraph). It has recently become clear that earlier reports of apparent Stroop interference impairments in ADHD did not control for age, IQ, and measures of nonexecutive function, and in particular, overlooked the contribution of impaired color naming (Nigg, 2005; Scheres et al., 2003; Tannock, Banaschewski, \& Gold, 2006). Here too it was in a condition that ADHD cases showed consistently longer RTs. Indeed, it was interesting to note that in our computer-aided task presentation, which is still not common in studies of the Stroop task, mean interference latencies were in fact descriptively (if non-significantly) $29 \%$ shorter for the cases compared to the comparison groups.

NP for color represents a quite different sort of interference from the Stroop conflicts between semantics and color features of a stimulus. NP indicates the slowing of response to a target that has just been presented as a non-target (where response was suppressed). NP was demonstrated on initial trial blocks by the two healthy subject groups, but it was attenuated over repeated presentations. ADHD cases did not show NP initially, but otherwise the RT progression across the test paralleled that of the other groups. In view of the sensitivity of the NP effect to trial block, it is not surprising that it was only recorded on trials with congruent stimuli. Presumably, the conflict provided by incongruent stimulus presentations masked the relatively minor interference of the NP effect. This interpretation is supported by a finding that NP measures in congruent and incongruent presentations showed positive and negative correlations with Stroop interference, respectively. The method of stimulus presentation (computer vs. cards), and the sensitivity to trial repetition and masking by incongruent stimuli may have contributed to the negative findings of some previous studies (Gaultney et al., 1999; Pritchard et al., 2006, 2007).

The expression of NP did not depend on either age or the severity of symptoms. This, along with the modest degree of NP impairment shown by the ADHD cases, would indicate that the task presentation was too simple to unmask group differences in the way the treatment of previous stimuli influences decision and response to current stimuli. Indeed, we observed that with practice across trials, it was not the suppression of response to the previous stimulus that guided current decisions, but that the previous stimulus and the current stimulus were the same (i.e., positive priming). This effect was less marked in ADHD cases. This may still reflect, as for impairments of NP shown by patients with limited damage to the right frontal lobe (Stuss et al., 1999), that there is a degree of hypofunction in regions controlling attention-related processes. Other impairments of cognitive control in ADHD cases have been attributed to hypoactive frontal function (Biederman, 
2005; Bush, Valera, \& Seidman, 2005). Confirmation of this finding will likely require a task with higher demands on working memory and the speed of processing.

\section{Variability}

Across a wide range of continuous performance, go/no-go, stop signal and working-memory tasks, ADHD cases show increased intra-individual variability in the speed of processing and responding to stimuli (Alderson, Rapport, \& Kofler, 2007; Klein, Wendling, Huettner, Ruder, \& Peper, 2006; Russell et al., 2006). In the present task, we not only confirmed that larger coefficients of variance were shown by the ADHD cases than controls, but also that this variability did not depend on the nature of the task condition and cognitive interference experienced (priming or congruency). However, it was clearly positively correlated with ratings of symptom severity. The feature of variability in go/no-go tasks has been attributed to altered top-down processing in fronto-parietal networks (Johnson et al., 2007) and particularly in brain-damaged patients to impaired right inferior/medial frontal function in the right hemisphere (Picton et al., 2007).

\section{Limitations}

Restriction of the selection of cases of ADHD to the combined subtype also restricts the conclusions that can be drawn about cognitive dysfunction that might be expected to be specific to the cluster of inattentive symptoms. It would be useful to examine the performance of cases diagnosed exclusively with the inattentive syndrome and to compare these with cases showing clear comorbid learning disabilities. However, it should be noted that cases with the combined subtype, as examined here, must express inattentive symptoms for diagnosis and may show severer symptoms of inattention (Gross-Tsur et al., 2006).
Further, we have not explicitly studied whether female cases respond like males. Although there is some evidence that females may show more inattentive symptoms (Gross-Tsur et al., 2006), others found little difference on executive functions (Rucklidge \& Tannock, 2002), and there are also other reports that suggest gender differences may reflect referral bias (Biederman et al., 2005). Further research is necessary to determine whether there are gender differences in the performance of tasks designed to test the influences of priming.

Use of a computerized version of the Stroop test means that that results may not be directly comparable with reports on the Stroop test with stimuli presented on cards. However, we felt that it was an advantage in test sensitivity to be able to record trial by trial RTs to millisecond accuracy rather than rely on averages of stimulus block presentations of cards measured with a resolution of the order of seconds. The duration of a trial was relatively fixed: It was externally paced and variation of trial length reflected merely the speed of response. It would be worthwhile in an attempt to replicate our study to examine the effect of manipulations of trial timing. First, the effect of self-paced timing, where the subject can initiate the next trial, may be expected to alleviate pressures on subjects expected to show cognitive impairment. Second, it would be useful to vary the inter-trial interval to see whether slower presentations facilitate distractibility with respect to faster ones, especially in the clinical group as has been reported for other task forms (review: Wiersema, van der Meere, Roeyers, Van Coster, \& Baeyens, 2006).

\section{Conclusions:}

We found that ADHD combined-type cases could express a modest and temporary reduction of the normal level of NP shown by siblings and independent 
controls in the absence of a significantly impaired Stroop interference, independent of age or severity of the symptoms shown. The nature and associations of the Stroop and NP interference processes

\section{References:}

Alderson, R. M., Rapport, M. D., \& Kofler, M. J. (2007). Attention deficit/ hyperactivity disorder and behavioral inhibition: A meta-analytic review of the stop-signal paradigm. Journal of Abnormal Child Psychology, 35, 745758.

American Psychiatric Association. (1994). Diagnostic and statistical manual of mental disorders (4th ed.). Washington, DC.

Asherson, P., \& Image Consortium. (2004). Attention deficit hyperactivity disorder in the post-genomic era. European Child and Adolescent Psychiatry, 13, 5066.

Bekker, E. M., Kenemans, J. L., Hoeksma, M. R., Talsma, D., \& Verbaten, M. N. (2005). The pure electrophysiology of stopping. International Journal of Psychophysiology, 55, 191-198.

Biederman, J. (2005). Attentiondeficit/hyperactivity disorder: A selective overview. Biological Psychiatry, 57, 1215-1220.

Biederman, J., Kwon, A., Aleardi, M., Chouinard, V.-A., Marino, T., Cole, H., et al. (2005). Absence of gender effects on attention deficit hyperactivity disorder: Findings in non-referred subjects. American Journal of Psychiatry, 162, 1083-1089.

Boonstra, A. M., Oosterlaan, J., Sergeant, J. A., \& Buitelaar, J. K. (2005). Executive functioning in adult ADHD: A metaanalytic review. Psychological Medicine, 35, 1097-1108.

Bush, G., Valera, E. M., \& Seidman, L. J. (2005). Functional neuroimaging of attention-deficit/hyperactivity disorder: were shown to differ and could potentially differentiate automatic cognitive inhibitory processes in cases of ADHD from normal under an increasing informationprocessing load.

A review and suggested future directions. Biological Psychiatry, 57, 1273-1284.

Chen, W., \& Taylor, E. A. (2006). Parental Account of Children's Symptoms (PACS), ADHD phenotypes and its application to molecular genetic studies. In R. D. Oades (Ed.), Attentiondeficit/hyperactivity disorder and the hyperkinetic syndrome: Current ideas and ways forward (pp. 3-20). Hauppauge, NY: Nova Science.

Conners, C. K. (2002). Manual for Conners' rating scales (rev. ed.) North Tonoawanda, NY: Multi-Health Systems.

Douglas, V. I. (1988). Cognitive deficits in children with attention deficit disorder with hyperactivity. In L. M. Bloomingdale \& J. A. Sergeant (Eds.), Attention deficit disorder: Criteria, cognition, intervention (pp. 65-82). London: Pergamon.

Gaultney, J. F., Kipp, K., Weinstein, J., \& McNeil, J. (1999). Inhibition and mental effort in attention deficit hyperactivity disorder. Journal of Developmental and Physical Disabilities, 11, 105-114.

Geurts, H. M., Verte, S., Oosterlaan, J., Roeyers, H., \& Sergeant, J. A. (2005). ADHD subtypes: Do they differ in their executive functioning profile? Archives of Clinical Neuropsychology, 20, 457477.

Goodman, R. (2001). Psychometric properties of the strengths and difficulties questionnaire. Journal of the American Academy of Child and Adolescent Psychiatry, 40, 1337-1345.

Gross-Tsur, V., Goldzweig, G., Landau,Y. E., Berger, I., Shmueli, D., \& Shalev, R. S. 
(2006). The impact of sex and subtypes on cognitive and psychosocial aspects of ADHD. Developmental Medicine and Child Neurology, 48, 901-905.

Johnson, K. A., Robertson, I. H., Kelly, S. P., Silk, T. J., Barry, E., Daibhis, A., et al. (2007). Dissociation in performance of children with ADHD and highfunctioning autism on a task of sustained attention. Neuropsychologia, 45, 2234-2245.

Klein, C., Wendling, K., Huettner, P., Ruder, H., \& Peper, M. (2006). Intrasubject variability in attention-deficit hyperactivity disorder (ADHD). Biological Psychiatry, 60, 1088-1097.

Marriott, M. (1998). Selective attention, negative priming, and hyperactivity: Investigating the " $A D$ " in $A D H D$. Unpublished doctoral dissertation, McMaster University, Hamilton, Ontario, Canada.

Nigg, J. T. (2005). Neuropsychologic theory and findings in attention deficit/ hyperactivity disorder: The state of the field and salient challenges for the coming decade. Biological Psychiatry, 57, 1424-1435.

Nigg, J. T., Hinshaw, S. P., \& Halperin, J. M. (1996). Continuous performance test in boys with attention deficit hyperactivity disorder: Methylphenidate dose response and relations with observed behaviors. Journal of Clinical Child Psychology, 25, 330-340.

Oades, R. D. (2000). Differential measures of sustained attention in children with attention-deficit/hyperactivity or tic disorders: Relationship to monoamine metabolism. Psychiatry Research, 93, 165-178.

Oades, R. D., Dittmann-Balcar, A., Schepker, R., \& Eggers, C. (1996). Auditory event-related potentials and mismatch negativity in healthy children and those with attention-deficit- or Tourette-like symptoms. Biological Psychology, 43, 163-185.
Ossmann, J. M., \& Mulligan, N. W. (2003). Inhibition and attention deficit hyperactivity disorder in adults. American Journal of Psychology, 116, 35-50.

Ozonoff, S., Strayer, D. L., McMahon, W. M., \& Filloux, F. (1998). Inhibitory deficits in Tourette syndrome: A function of comorbidity and symptom severity. Journal of Child Psychiatry, 39, 1109-1118.

Picton, T. W., Stuss, D. T., Alexander, M. P., Shallice, T., Binns, M. A., \& Gillingham, S. (2007). Effects of focal frontal lesions on response inhibition. Cerebral Cortex, 17, 826-838.

Pritchard, V. E., Healey, D., \& Neumann, E. (2006). Assessing selective attention abilities in ADHD, highly creative and normal young children via Stroop interference and negative priming effects. In C. M. Fletcher-Flinn \& G. M. Habermann (Eds.), Cognition, language and development: Perspectives from New Zealand (pp. 207-224). Brisbane: Australian Academic Press.

Pritchard, V. E., \& Neumann, E. (2004). Negative priming effects in children engaged in non-spatial tasks: Evidence for early development of an intact inhibitory mechanism. Developmental Psychology, 40, 191-203.

Pritchard, V. E., Neumann, E., \& Rucklidge, J. J. (2007). Interference and negative priming effects in adolescents with attention deficit hyperactivity disorder. American Journal of Psychology, 120, 91-122.

Rucklidge, J. J., \& Tannock, R. (2002). Neuropsychological profiles of adolescents with ADHD: Effects of reading difficulties and gender. Journal of Child Psychology and Psychiatry, 43, 988-1003.

Russell, V. A., Oades, R. D., Tannock, R., Auerbach, J., Killeen, P. R., Johansen, E. B., et al. (2006). Response variability in attention deficit/hyperactivity disorder: 
A neuronal and glial energetics hypothesis. Biomed Central: Behavioral and Brain Functions, 2, 30.

Sattler, J. M. (1992). Assessment of children: Behavioral and clinical applications (3rd ed.) San Diego, CA: J. M. Sattler.

Scheres, A., Oosterlaan, J., Swanson, J. M., Morein-Zamir, S., Meiran, N., Schut, H., et al. (2003). The effect of methylphenidate on three forms of response inhibition in boys with AD/HD. Journal of Abnormal Child Psychology, 31, 105-120.

Schwartz, K., \& Verhaeghen, P. (in press). ADHD and Stroop interference from age 9 to age 41 years: A meta-analysis of developmental effects. Psychological Medicine.

Simone, P. M., \& McCormick, E. B. (1999). Effect. Visual Cognition, 6, 587-606.

Stuss, D. T., Toth, J. P., Franchi, D., Alexander, M. P., Tipper, S., \& Craik, F. I. M. (1999). Dissociation of attentional processes in patients with focal frontal and posterior lesions. Neuropsychologia, 37, 1005-1027.

Tannock, R., Banaschewski, T., \& Gold, D. (2006). Color naming deficits and attention-deficit/hyperactivity disorder: A retinal dopaminergic hypothesis. Behavioral and Brain Functions, 2, 4.

Taylor, E. A., Sandberg, S., Thorley, G., \& Giles, S. (1991). The epidemiology of childhood hyperactivity. Oxford, UK: Oxford University Press.

Taylor, E. A., Schachar, R. J., Thorley, G., \& Wieselberg, M. (1986). Conduct disorder and hyperactivity: 1. Separation of antisocial conduct in British child psychiatric patients. British Journal of Psychiatry, 149, 760-767.

Tipper, S. P., Bourque, T. A., Anderson, S. H., \& Brehaut, J. C. (1989). Mechanisms of attention: A developmental study. Journal of Experimental Child Psychology, 48, 353-378.
Tipper, S. P., \& McClaren, J. (1990). Evidence for efficient visual selectivity in children. In J. T. Enns (Ed.), The development of attention: Research and theory (pp. 197-210). Amsterdam: Elsevier.

van der Meere, J. J., Wekking, E., \& Sergeant, J. A. (1991). Sustained attention and pervasive hyperactivity. Journal of Child Psychology and Psychiatry, 32, 275-284.

Wiersema, J. R., van der Meere, J. J., Roeyers, H., Van Coster, R., \& Baeyens, D. (2006). Event rate and event-related potentials in ADHD. Journal of Child Psychology and Psychiatry, 47, 560-567. 